\title{
The plain truth about tobacco packaging
}

\section{Gerard Hastings, ${ }^{1}$ Karine Gallopel-Morvan, ${ }^{2}$ Juan Miguel Rey ${ }^{3}$}

Hymenopus coronatus (the Malaysian preying mantis) has a cunning hunting technique. It disguises itself as an orchid; its four walking legs are exquisite replicas of petals and its lethal jaws blend into the background. This makes it beautiful to behold, but for the lizards and insects that are its prey, ruthless and deadly. What looks like a flower, and an enticing source of nectar, is actually a death trap.

The tobacco industry has learnt well from $H$ coronatus. It camouflages its deadly product in elegantly decorated packages making them look on the one hand uniquely attractive and on the other just like any branded product. Thus they acquire exclusivity and legitimacy. Like $H$ coronatus, tobacco companies also succeed in hunting and killing small creatures. It is abundantly clear that young people are drawn into smoking by branding and that liveried packs play an active role in this process.

The UK Government is therefore to be applauded for its proposal to mandate plain packaging for cigarettes. ${ }^{1}$ This would involve removing all distinctive signs from packs leaving only the name of the brand in a standard colour and font, along with the legally mandated information. $^{2}$ It's the equivalent of turning $H$ coronatus into a piece of couch grass.

The evidence for the harm done by liveried packs is clear. The first concerns emerge from the business literature, which emphasises that the pack in lots of product categories has become far more than a simple container: ${ }^{3}$ it also adds value, makes the product distinctively attractive and stimulates purchase and repeat purchase. ${ }^{4}$ It has become a key long-term marketing investment ${ }^{5}$ that "allows the brand to develop its message to the consumer and to act as a valuable

\footnotetext{
${ }^{1}$ University of Stirling and the Open University, Stirling, Scotland, UK; ${ }^{2}$ University of Rennes 1 , School of Business Administration, Rennes, France; ${ }^{3}$ University of Cadiz, School of Business Administration, Cadiz, Spain

Correspondence to: Gerard Hastings, Institute for Social Marketing and the Centre for Tobacco Control Research, University of Stirling and the Open University, Stirling FK9 4LA, Scotland, UK;

gerard.hastings@stir.ac.uk
}

form of promotion of the brand name and values". ${ }^{\circ}$

In the case of tobacco, the pack has been used for years to generate evocative images such as luxury, freedom, glamour, status and masculinity or femininity, ${ }^{7-9}$ as well as to give smokers false comfort about health consequences. ${ }^{10}$ It is also the marketing tool with most direct links to the consumer ${ }^{11}$ and its power is increased because cigarettes are "badge products" which are conspicuously consumed, particularly by the young, to make public statements about the user's self image and identity. ${ }^{11}{ }^{12}$ Furthermore, as other forms of marketing have been removed, the pack has become increasingly important to the tobacco industry, ${ }^{13}{ }^{14}$ providing a vital communication platform ${ }^{15}$ and link to other forms of marketing communication such as sponsorship. ${ }^{16}$

Consumer research confirms this marketing power. Studies of the whole population show that liveried packs evoke positive images ${ }^{17}$ and, conversely, that generic ones make the product and its perceived consumer less fashionable and attractive. $^{18-22}$ The young are particularly susceptible to these effects. Large-scale research in the UK has demonstrated that even after advertising is banned (the 2004 Tobacco Advertising and Promotion Act prohibited tobacco advertising in the UK), branding continues to drive teen smoking $^{23}$ and that awareness of packaging and new pack design is a key element of this ongoing marketing. ${ }^{24}$ An industry analyst interviewed in the latest issue of the trade magazine Tobacco Journal International (TJI) confirmed this marketing value, commenting that "more than half the brand impact is in the design of the cigarette packet". ${ }^{25}$ It is not surprising then that the leading business website Brand Republic is trailing the fact that UK "tobacco brands are putting packaging design at the heart of their marketing strategies", noting that Gallaher and Imperial Tobacco have introduced design innovations. $^{26}$

It is also clear that children, especially those from deprived backgrounds, find tobacco brands particularly enticing.
Scheffels shows how "cigarette brands and cigarette package designs are given meaning in relation to personal characteristics, to social identity and to positions in hierarchies of status..." ${ }^{25}$ In this way they become props for self expression. Roper and $\mathrm{Shah}^{27}$ confirm the symbolic importance of the brand among preadolescents allowing them to feel part of their reference group and, in the case of less well off children, helping them disguise their disadvantage. Similarly, research in North America reveals how young people use branded cigarettes to appear fashionable, popular and smart, ${ }^{18}$ and the most recent research in Australia ${ }^{17}$ reinforces the evidence that plain packs - the plainer the better - can strip away these layers of deceptive imagery.

As if this poisonous seduction was not enough, the pack livery also acts as a spoiler, distracting attention from the health warning. ${ }^{28-31}$ Much time and effort has been put into strengthening these and they are a valuable and effective public health measure, and yet clever pack designs are allowed to subvert them.

None of this is wasted on the tobacco companies. Analysis of their internal documents shows that they fully appreciate the marketing value of their packs and will fight to keep them. ${ }^{32}$ They argue that any restriction would represent an unfair interference in their creative and commercial freedom and infringe property rights. ${ }^{25}$ But these freedoms are negated by the harm being done to public heath and the need to protect young people. Furthermore, the pharmaceutical market provides an interesting precedent: powerful medicines, particularly addictive ones such as psychotropic drugs, routinely come in plain packs. ${ }^{2}$ Tobacco is also extremely addictive, carries enormous health risks, but unlike a medicine, provides no objective benefits.

Interestingly, despite their obvious opposition to generic packaging the tobacco industry does see it as a very real possibility. In their 2007 Standard Industrial Classification (SIC) submission Philip Morris lists it as 1 of 10 "significant regulatory developments [that] will take place over the next few years in most of our markets". ${ }^{33}$ Similarly, the industry analyst in TJI says that while "it is unlikely in the next year or 2, on a 5- or 10 -year view, then I think it is certainly possible". ${ }^{25} \mathrm{He}$ also notes that "it is important to remember that every anti-tobacco proposal that has been consulted on by the UK government in the last 10 years has been implemented" and 
(inadvertently) that the UK would be performing a valuable service to global public health because "if it goes ahead in the UK, it will sweep across many countries around the world in a few years". ${ }^{25}$

It is, then, the time for action. $H$ coronatus is a wonderful natural phenomenon; tobacco branding is an obscene man-made corruption of it. This lethal product should be stripped of its enticing camouflage by mandating plain packaging.

\section{Competing interests: None}

Tobacco Control 2008;17:361-362.

doi:10.1136/tc.2008.027755

\section{REFERENCES}

1. Department of Health. Consultation on the future of tobacco control. London, UK: Department of Health, 2008.

2. Freeman B, Chapman S, Rimmer M. The case for the plain packaging of tobacco products. Addiction 2008:103:580-90.

3. Underwood RL, Klein NM, Burke RR. Packaging communication: attentional effects of product imagery. J Product Brand Manage 2001;10:403-22.

4. Meyers H, Lubliner MJ. The marketer's guide to successful package design. Chicago, Illinois, USA NTC Business Books, 1998.

5. Biondo CG. Creating brand champions: a look at brand packaging design during the past 40 years. The Advertiser 1998;0ct

6. Roper S, Parker C. How (and where) the mighty have fallen: branded litter. J Marketing Management 2006;22:473-87.

7. Thibodeau M, Martin J. Smoke gets in your eyes: a fine blend of cigarette packaging and design. New York, USA: Abbeyville Press, 2001.

8. Scheffels J. A difference that makes a difference: young adult smokers' accounts of cigarette brands and package design. Tob Control 2008;17:118-22.

9. Cunningham R, Kyle K. The case for plain packaging Tob Control 1995;4:80-6.
10. Devlin E, Eadie D, Angus K. Low tar product category. Prepared for NHS Health Scotland. Glasgow, UK: Centre for Tobacco Control Research, 2003. http://www.tobaccopapers.com/casestudies/index. htm\#lowtarproduct (accessed 15 October 2008).

11. Hammond D. Tobacco labelling \& packaging toolkit: a guide to FCTC Article 11. Tobacco Labelling Resource Centre 2008. http://www.igloo.org/ tobacco labelling (accessed 15 October 2008).

12. D'Avernas JR, Northrup D, Foster MK, et al. Cigarette packaging and event marketing increases the attractiveness of smoking: a study of youth. Working paper 28. Toronto, Ontario, Canada: The Ontario Tobacco Research Unit, 1997.

13. Chapman S. Public health advocacy and tobacco control: making smoking history. Oxford, UK: Blackwell, 2007.

14. Wakefield $\mathbf{M}$, Letcher T. My pack is cuter than your pack. Tob Control 2002:11:154-6.

15. Slade J. The pack as advertisement. Tob Control 1997;6:169-70.

16. Carr-Cregg MRC, Gray AJ. 'Generic' packing: possible solution to the marketing of tobacco to young people. Med J Australia 1990;153: 685-6.

17. Wakefield MA, Germain D, Durkin SJ. How does increasingly plainer cigarette packaging influence adult smokers' perceptions about brand image? An experimental study. Tob Control 2008;17:416-21.

18. Rootman I, Flay BR. A study on youth smoking: plain packaging, health warnings, event marketing and price reductions. Toronto, Ontario, Canada: University of Toronto, University of Illinois at Chicago, York University, Ontario Tobacco Research Unit, Addiction Research Foundation, 1995.

19. Centre for Health Promotion. Effects of plain packaging on the image of tobacco products among youth. Toronto, Ontario, Canada: University of Toronto, 1993.

20. Madill-Marshall J, Goldberg MW, Gorn GJ, et al. Two experiments assessing the visual and semantic images associated with current and plain cigarette packaging. Adv Consumer Res 1996;23:267-8.

21. Donovan RJ. Smokers' and non-smokers' reactions to standard packaging of cigarettes. Perth, Australia: University of Western Australia, 1993.

22. RBJ Health Management Associates. Impact of plain packaging of tobacco on youth perceptions and behaviour. Report of study 1. Toronto, Ontario, Canada: RBJ Health Management Associates, 1993.

23. Moodie C, Mackintosh AM, Brown A, et al. Tobacco marketing awareness on youth smoking susceptibility and perceived prevalence before and after an advertising ban. Eur J Public Health 2008;18:484-90.

24. Centre for Tobacco Control Research (CTCR)

Point of sale display of tobacco products. London, UK: Cancer Research UK, 2008. http://info. cancerresearchuk.org/images/pdfs/ tobcon pointofsalereport laccessed 15 October 2008).

25. Rossell S. Little hope in appealing to natural justice: TJI interview with Adam Spielman. Tob J Int 2008;4. http://www.tobaccojournal.com/

Little hope in appealing to natural justice.49195. 0.html (accessed 15 October 2008)

26. Bokaie J. Tobacco firms in pack design work. Brand Republic, 2008. http://www.brandrepublic.com/ News/846210/Tobacco-firms-pack-design-work/ (accessed 15 October 2008).

27. Roper S, Shah B. Vulnerable consumers: the social impact of branding on children. Equal Opportunities Int 2007;:26:712-28.

28. Environics Research Group. Consumer research on the size of health warning messages - quantitative study of Canadian youth. Health Canada. http://www smoke-free.ca/warning/warningsResearch/ environics-size-youth-english.pdf laccessed 15 October 2008).

29. Goldberg ME, Liefeld J, Madill J, et al. The effect of plain packaging on response to health warnings. Am J Public Health 1999;89:1434-5.

30. Beede $\mathbf{P}$, Lawson R, Shepherd M. The promotional impact of cigarettes packaging: a study of adolescent responses to cigarette plain-packs. Dunedin, New Zealand: University of Otago, 1991.

31. Beede $\mathbf{P}$, Lawson R. The effect of plain packages on the perception of cigarette health warnings. Public Health 1992;106: 315-22.

32. Wakefield M, Morley JK, Horan JK, et al. The cigarette pack as image: new evidence from tobacco industry documents. Tob Control 2002:11:73-80.

33. Philip Morris International Inc. Registration filing to the SEC (form 10-12B). Philip Morris International Inc, 2007;11-12.

\section{Access all our original articles online even before they appear in a print issue!}

Online First is an exciting innovation that allows the latest clinical research papers to go from acceptance to your browser within days, keeping you at the cutting edge of medicine.

Simply follow the Online First link on the homepage and read the latest Online First articles that are available as unedited manuscripts in downloadable PDF form. The articles are peer reviewed, accepted for publication and indexed by PubMed but not yet included in a journal issue, so you'll be among the first to read them! 